\title{
CORRECTION
}

\section{Correction to: Risk and Protective Factors for Social Anxiety Among Sexual Minority Individuals}

\author{
Conor P. Mahon ${ }^{1}\left[\right.$ D $\cdot$ John E. Pachankis ${ }^{2} \cdot$ Gemma Kiernan $^{3} \cdot$ Pamela Gallagher $^{1}$
}

Published online: 8 March 2021

(c) Springer Science+Business Media, LLC, part of Springer Nature 2021

Correction to: Archives of Sexual Behavior https://doi.org/10.1007/s10508-020-01845-1

The figure given in Row 7, Column 9 in Table 2 in this article as originally published was incorrect.

The correct correlation is $-.43 * *$ (not $.43^{* *}$ ).

The original article has been corrected.

Publisher's Note Springer Nature remains neutral with regard to jurisdictional claims in published maps and institutional affiliations.

The original article can be found online at https://doi.org/10.1007/ s10508-020-01845-1.

Conor P. Mahon conor.mahon24@mail.dcu.ie

1 School of Psychology, Dublin City University, 620 Collins Ave Ext, Glasnevin, Dublin 9 D09 X984, Ireland

2 Department of Social and Behavioral Sciences, Yale School of Public Health, New Haven, CT, USA

3 School of Nursing, Psychotherapy and Community Health, Dublin City University, Dublin, Ireland 